\author{
MARTI, LEZAMA LIMA \\ Y EL USO FIGURATIVO DE LA HISTORIA
}

\author{
POR \\ GUSTAVO PELLON \\ University of Virginia
}

\begin{abstract}
But actually there is no choice between historical and hidden meaning; both are present. The figural structure preserves the historical event while interpreting it as revelation; and must preserve it in order to interpret it.
\end{abstract}

Aucrbach, "Figura"

No sorprenden, en la obra de José Lezama Lima, las reiteradas apariciones de José Martí. Sorprende, en cambio, lo esparcido y fugaz de esa presencia, y el hecho de que Lezama, quien le dedicara sendos ensayos a Julián del Casal y a Juan Clemente Zenea, nunca escribió lo que Fina García Marruz ha llamado su "ensayo definitivo sobre Marti". A pesar de esa ausencia, que se hace sentir en tan persistente buscador de lo cubano y lo americano, cuando Martí aparece es para ocupar el puesto máximo que Lezama puede otorgar. Es el fundador de la última de las "Eras imaginarias":

\footnotetext{
1 "Julián del Casal" (1941) Analecla del reloj (1953), "Juan Clemente Zenea" (1967) La canlidad hechizada (1970). Ver José Lezama Lima, Obras complelas 2 (México: Aguilar, 1977) 65-99; 1039-1108, respectivamente. Para las obras de Lezama me refiero siempre a la edición de las Obras completas.

Sobre Martí y Lezama se ha escrito poco. Véase de Pedro Barreda, "El criollo arco largo de Paradiso: Lezama y la recscritura de la oralidad", Texto Crítico 12, 34-35: 262-289; Fina García Marruz, "La poesía es un caracol nocturno (En torno a Imagen y posibilidadl)", en Coloquio internacional sobre la obra de José Lezama Lima, 1 (Madrid: Fundamentos, 1984) 243-275; Eloísa Lezama Lima, "Introducción" Paradiso (Madrid: Cátedra, 1980) 19, 45, 57; Alessandra Riccio, "El diario de Martí en José Lezama Lima", Unión 2 (1985): 96-100; Cintio Vitier, "Introducción a la obra de José Lezama Lima", en José Lezama Lima, Ob̉ras complelas 1 (México: Aguilar, 1975) XXVII-XXVIII, XLI. XIIV, LXIII-LXIV. Gancía Marruz relata una anćcdota sobre la falta de un "ensayo definitivo" de Lezama sobre Martí:

El, que se atrevió con todos los temas, cuando le preguntabamos: ¿Cuándo nos va a dar al fin su ensayo definitivo sobre Martf?, contestaba invariablemente, avergonzando a los que hemos nutrido la ya copiosa bibliografía martiana: "Todavia, todavía debo esperar" (p. 274).
} 
La última era imaginaria, a la cual voy a aludir en esta ocasión, es la posibilidad infinita, que entre nosotros la acompaña José Martí. Entre las mejores cosas de la Revolución cubana, reaccionando contra la era de la locura que fue la etapa de la disipación, de la falsa riqueza, está el haber traído de nuevo el espíritu de la pobreza irradiante, del pobre sobreabundante por los dones del espíritu. El siglo XIX, el nuestro, fue creador desde su pobreza. Desde los espejuelos modestos de Varela, hasta la levita de las oraciones solemnes de Marí, todos nuestros hombres esenciales fueron hombres pobres. Claro que hubo hombres ricos en el siglo XIX, que participaron del proceso ascensional do la nación. Pero comenzaron por quemar su riqueza, por morirse en el destierro, por dar en toda la extensión de sus campiñas un campanazo que volvía a la pobreza más esencial, a perderse en el bosque, a lo crrante, a la lejanía, a comenzar de nuevo en una forma primigenia y desnuda $(\mathrm{Z}, 838-839)$.

En este pasaje de "A partir de la poesía" (1960), Lezama ve en el Movimiento 26 de Julio el cumplimiento de la promesa ética de Martí, frustrada por la República, y también una respuesta a su propia profesión de fe en la fertilidad de esa promesa, años antes, en "Secularidad de Mart" (1953), cuando la dictadura de Batista más la desmentía:

Origenes reúne un gru po de escritores reverentes para las imágenes de Martí. Sorprende en su primera secularidad la viviente fertilidad de su fuerza como impulsión histórica, capaz de saltar las insuficiencias toscas de lo inmediato, para avizorarnos las cú pulas de los nuevos actos nacientes ${ }^{2}$.

Martí es la culminación de la historia cubana porque ofrece "la posibilidad infinita", pero, a la vez, representa para Lezama la plenitud de la palabra cubana:

En José Martí culminaron todas las tradiciones cubanas de la palabra .... Martí retomó la tradición, profundizó el conocimiento de nuestros clásicos, se empapó

2 José Lezama Lima, Imagen y posibilidad, Selección, prólogo y notas de Ciro Bianchi Ross (La Habana: Letras Cubanas, 1981) 198. Véase el examen de la selección de ensayos y de la actitud de Lezama ante la Revolución que hace Enrico Mario Santí en "La invención de Lezama Liman, Vuella 102 (1985): 45-49. A juzgar por las cartas, principalmente a su hermana Eloísa, el entusiasmo que Lezama demostró por la Revolución al principio parece haberse atenuado hacia el final de su vida, pero nunca se ha publicado ninguna declaración suya al respecto. Las cartas si, expresan su frustración ante la decisión del gobierno de no permitirle aceptar las muchas invitaciones a viajar al extranjero que recibió después de la publicación de Paradiso. Véase José Lezama Lima, Carlas (1939-1976), edición e introducción de Elósa Lezama Lima (Madrid: Origenes, 1979) 252-253, 257, 259, 261, 270. En Coloquio inlernacional sobre la obra de José Lezama Lima, 1, José Alvarez Bravo insiste en la censura y retirada de Paradiso en 1966 y el aislamiento al cual Lezama fue sometido después del caso Padilla por el "establishment" literario oficial de Cuba, pp. 87-97. A seguir aparece una denuncia vehemente del trabajo de Alvarez Bravo por Cintio Vitier y Fina García Marruz, 99-102. 
de las zonas más creadoras de nuestra expresión. Fue un reavivador del idioma, es decir, el español, desde la época de los grandes clásicos, Santa Teresa, Quevedo, Gracián, no volverá a lucir tan ágil, flexible y novedoso como on Martí .... Martí reloma todas las tradiciones cubanas y las lieva a su plenitud .... Martí puso al servicio de su causa los recursos más cautivadores del arte y de la inteligencia .... Fue suerte inefable para todos los cubanos que aquél que trajo las innovaciones del verbo las supiese encarnar en la historia. Fue suerte también que el que conmovió las esencias de nuestro ser fue el que reveló los secretos del hacer. El verbo fue así la palabra y el movimiento del devenir $(2,1036-1038)$.

La expresión de Lezama, tomada del evangelio según San Juan, indica claramente la analogía que motiva este pasaje de "Prólogo a una antología" (1965), lo que Cristo es para el esquema cristiano de la historia, Martí lo es para la historia de Cuba. Marti es el momento en el cual la palabra y la acción se funden, y al fundirse, fundan. Martí, el fundador, supo traducir la palabra en acción con su muerte, y por eso las obras que obsesionan a Lezama son sus últimos escritos, los Diarios (de Monte Cristi a Cabo Haitiano, y de Cabo Haitiano a Dos Ríos). En "Paralelos: La pintura y la poesía en Cuba (siglos XVIII y XIX)"(1966), dice que el Diario de Martí es "el más grande poema escrito por un cubano, donde las vivencias de su sabiduría se vuelcan en una dimensión colosal" $(2,968)$. Según Lezama, en ellos queda constancia de la purificación de Martí y de su preparación para la muerte, a la vez que se depura su palabra. De ahí que Lezama repetidamente asocie los diarios de Martí con El libro de los muertos egipcio ${ }^{3}$.

Lezama encuentra una clave reveladora (un ejemplo de "vivencia oblicua") en la yuxtaposición del "jarro hervido en dulce, con hojas de higo" con el cual termina abruptamente la escritura de Martí, con los pasteles de azafrán que "los moradores subterráneos saborean" según el vademécum de los muertos egipcios4. Lo inesperado suscita la revelación para Lezama. Así la extraña presencia de las hojas de higo de la antigüedad bíblica y clásica en plena manigua cubana, tiene su respuesta en el hispánico (y cubano) azafrán del libro egipcio. Estos dos emblemas le abren a Lezama una suerte de escala de Jacob que comunica dos "Eras imaginarias": la de los egipcios con la de la "posibilidad

${ }^{3}$ Lezama asocio muchas veces los diarios de Martí con el Libro de los muerlos. En Inlerrogando a Lezama Lima (Barcelona: Anagrama, 1971) lo menciona en entrevistas con Eugenia Neves (p. 56) y con Jean-Michel Fossey (p. 70). También aparece esa comparación en "El romanticismo y el hecho americano", La expresión americana (1957) $(2,346)$, y en "Paralelos" $(2,967)$. Los pasteles de azafrán que tanto impresionaron a Lezama aparecen en el capítulo $17 \mathrm{del}$ Libro de los muertos. Ver The Book of the Dead, E. A. Wallis Budge, trans. (Londres: Routledge \& Kegan Paul, 1974), reimpresión de la edición de 1909) 109.

4 Interrogando a Lezama Lima, 56. 
infinita" representada por Martí. Lezama conjuga el valor emblemático del prócer cubano con el del dios egipcio Osiris, protagonista principal del Libro de los muertos, a quien se le considera "el muerto entre los vivos y el vivo entre los muertos" ${ }^{\prime 5}$. Osiris fue muerto, descuartizado, y echado al agua por su hermano Set, pero logró la resurreción y la inmortalidad gracias a la devoción de su hermana y esposa Isis, quien recogió los pedazos y momificó al que entonces se convirtió en el dios de los muertos.

Para Lezama, Martí viene a ser una versión cubana de Osiris, ya en sus Diarios habla como si estuviera muerto, pero se trasluce una gran confianza mística que su muerte cercana será un comienzo ${ }^{6}$. Otras concurrencias en los hechos de las muertes de Osiris y Martí le dan rica resonancia a la comparación: el papel importante del agua (el Nilo/el Cauto y el Contramaestre), ambos mueren por mano de un hermano hostil (Set/las balas españolas), ambos cadáveres sufren un tipo de fragmentación, son embalsamados, y enterrados varias veces. No hay que insistir en el perfecto engranaje de los paralelos, ya que para Lezama lo que cuenta es lo sugestivo del agrupamiento. Es más, como el valor figurativo de la historia le importa más que la veracidad del dato histórico, Lezama se encandila con paralelos que simplemente no existen en la historia. Por ejemplo, en otro ensayo Lezama describe una decapitación de Martí que si bien concuerda con el descuartizamiento de Osiris, no se apoya en testimonio histórico:

Vemos cómo ha sido arrastrado después de muerto bajo la lluvia, cómo al desplomarse del alazán algunos que lo vieron dicen que aún gemía, cómo ha sido enterrado y desenterrado ... cómo su cabeza separada del tronco, como en los alardes chillantes de una caballería mongólica, ha sido mostrada a la entrada de la ciudad?

Como lo demuestra el esquema de las "Eras imaginarias" que Lezama elaboró y al que fue añadiendo toda su vida, para él, el valor mayor de la historia y de la cultura en general es su potencia para irradiar imágenes.

5 Jose Lezama Lima, "Las cras imaginarias", 2: 864.

${ }^{6}$ Al asociar a Martí con Osiris, Lezama no hace más que desarrollar en otro registro la comparación con Cristo. Como Cristo, Osiris redime a sus seguidores con su muerte y resurrección y les ofrece la inmortalidad si acatan sus preceptos. Otros mitos análogos son los de Adonis, y Dionisio. Veánse los capítulos pertinentes en el famoso libro de James George Frazer, The Golden Bough (New York: Macmillan, 1963, reimpresión de la edición de 1922).

${ }_{7}^{7}$ "Lectura" en Imagen y posibilidad, 103-104. La suerte que corrió el cadáver de Martí es bastante distinta. El cadáver de Martí fue enterrado al día siguiente de muerto en Remanganaguas. Cinco días después fue desenterrado. Se intentó embalsamarlo, y fue expuesto al público en el Parque de Palma Soriano. Por último fue inhumado en el Cementerio de Santa Efigenia de Santiago de Cuba, el 27 de mayo. Vease el relato detallado que da Jorge Quintana en la Biobibliografía de su edición de las obras completas de Marti (Caracas: 1964), CCLXVIII-CCLXXII. 


\section{LEZAMA LIMA Y EL USO FIGURATIVO DE LA CULTURA}

Tal vez lo más desconcertante de la obra de Lezama sea un ejercicio de la lectura y de la escritura que disuelve la dicotomía fundamental de la tradición literaria de occidente entre naturaleza y cultura. Lo que sobrecoge al lector de Lezama no es que su obra se nutra indistintamente de la naturaleza y de la cultura, sino que trate a la cultura como otros artistas tratan a la naturaleza.

Su actitud idiosincrática hacia la cultura la explican su concepto de la creación poética y su concepto de lo americano. La creación poética para él se centra totalmente en la expresión metafórica, y ambas, la naturaleza y la cultura, le sirven de canteras para sus imágenes. En su obra, la marea, las estrellas, un fibroma, el asma, son transformados en emblemas que cifran aspectos de su poética y de su ética, pero también lo son el nombre de un artista, una novela, un cuadro, un personaje histórico, y hasta un crítico literario. La actitud de Lezama hacia la cultura sólo es comprensible si se logra apreciar el significado especial que tiene la naturaleza para él. La naturaleza evoca el libro del Génesis, el jardín del Edén, la caída de Adán y Eva. La poesía (o la vida, para él es lo mismo) tiene como meta la recuperación de la naturaleza perdida por el pecado original, como lo explica en "Pascal y la poesía":

Hay inclusive como la obligación de devolver la naturaleza perdida. De fabricar naturaleza, no de recibirla como algo dado. "Como la verdadera naturaleza se ha perdido - dice Pascal-, todo puede ser naturaleza" ... Si la pérdida de la naturaleza se debió al pecado, no lo puede ser en el hombre el afán de colocar en el sitio de la naturaleza después de la caída, otra naturaleza segregada o elaborada. En el sitio de esa naturaleza caida, enemiga del hombre, no se percibe un misterio ni u na claridad, ni el misterio que desliza la sustancia de la fe ni la momentánea claridad que se deriva de penetrar en las esencias quiditarias $(2,564)$.

La naturaleza no ha de aceptarse como algo dado; es necesario someterla a una transformación mediante el arte, lo cual, para Lezama, implica que ha de traducirse en imágenes culturales, imágenes poéticas cuyo propósito es darles al poeta y a su lector acceso a la imago, concepto que vincula el lenguaje figurativo a la revelación mística:

Determinada masa de entidades naturales o culturales, adquieren en un súbito, inmensas resonancias. Entidades como las expresiones, fábulas milesias o ruinas de Pérgamo, adquieren en un espacio contrapunteado por la imago y el sujeto metafórico, nueva vida, como la planta o el espacio dominado. De ese espacio contrapunteado depende la metamorfosis de una entidad natural en cultural imaginaria. Si digo piedra, estamos en los dominios de una entidad natural, pero si digo piedra donde lloró Mario, en las ruinas de Cartago, constituimos una entidad cultural de sólida gravitación. La fuerza de ur- 
dimbre y la gravitación caracterizan ese espacio contrapunteado por la imago, que le presta la exlensión hasta donde ese espacio tiene fuerza animista en relación con esas entidades $(2,283)$.

La naturaleza tiene que ser creada de nuevo como cultura, pero esa cultura, entonces, es tratada paradójicamente por Lezama como si fuese algo dado.

La causalidad, a su parecer, no tiene vigencia en la cultura, y esto tiene consecuencias radicales para su práctica de consumo cultural. Sin causalidad, no hay cuestión de influencia, y por ende no hay concepto dinámico de la cul tura. Para Lezama la historia intelectual tiene más que ver con inmanencia e irradiación, que con evolución. La cultura es una asamblea de ideas y posiciones, emblemas autónomos que reverberan y se confirman entre si, más en el espacio que en el tiempo. La cultura, para él, es algo dado, como la naturaleza lo es para la mayoría de nosotros. Esta actitud es lo que explica su crítica del concepto de la influencia literaria, y a la vez, lo que parece ser su total despreocupación sobre influencias literarias en su obra ${ }^{8}$.

Lezama sugiere que la importancia de la influencia literaria ha sido exagerada:

El problema de las influencias es casi inapresable porque el hombre es un instante sensorial infinitamente polarizado. A veces una palabra, una sentencia apenas entreoida nos ilumina y logra configurar formas de expresión. Casi siempre lo que apenas conocemos es lo que logra influenciarnos, después volvemos, insistimos, adquirimos tal vez lo que los pedantes llaman conocimiento exhaustivo, pero ya eso no produce en nosotros resonancias ni. vibraciones ${ }^{9}$.

La crítica de la noción de la influencia literaria tendría buena acogida en el campo de la teoría literaria contemporánea, pero pocos se subscribirían a la alternativa propuesta por Lezama: la creencia en el carácter epifánico de la creación artística. En la literatura como en la vida, Lezama mantiene que la verdad no se alcanza por medio de la investigación exhaustiva y la disciplina de la lógica. La verdad se alcanza mediante una disciplina de receptividad: la verdad se dispensa como la gracia espiritual. Aunque Lezama lo enriquece con resonancias orientales, en particular las del budismo Zen, su concepto antirracional de la iluminación es, en su esencia, cristiano y tiene sus raíces en el pensamiento de San Agustín. La verdad no puede ser arrebatada por la razón, sino que ha de recibirse - según la metáfora agustiniana- con "el oído del corazón"10.

${ }^{8}$ Me reficro a "la ansiedad de la influencia" estudiada por Harold Bloom en su The Anxiely of Influence (Nueva York: Oxford, 1975).

- Interrogando a Lezama Lima 52.

${ }^{10}$ La frase "el ofdo del corazón" y sus variantes es recumente en las Confesiones de San Agustín. Ver, por ejemplo, libro 4, capítulo 5, y libro 7, capítulo 10. 
La aseveración de Lezama, de que el conocimiento exhaustivo basado en la lectura cuidadosa tiende a influirnos e iluminarnos menos que lo que apenas conocemos, pone en tela de juicio la noción misma de influencia literaria y socava los más básicos preceptos del historicismo literario. Al valorar la intuición sobre la erudición, este concepto de la relación entre los autores y la literatura de hecho borra la distinción entre interpretaciones válidas e inválidas. En este respecto Lezama parece acercarse mucho al parecer de Iarold Bloom, quien afirma: "Poetic Influence - when it involves two strong, authentic poets-, always proceeds by a misreading of the prior poet, an act of creative correction that is actually and necessarily a misinterpretation"11. La preferencia lezamesca por la frase aislada y entreoída efectivamente descarta la noción de contexto en la interpretación literaria. Para Lezama el único contexto válido es la conciencia del lector.

Su respuesta iconoclasta ante las restricciones del estudio tradicional de las influencias es la inversión de la relación entre causa y efecto:

Las influencias no son de causas que engendran efectos, sino de efectos que iluminan causas. Proust hace que se lean las Memorias de Saint-Simon o que se vuelva al sentido del relato de Las mil y una noches, como una consecuencia de un acto excepcional, pero desgraciadamente los profesores, que son los gendarmes obligados de estos temas, gustan más de las cadenas causales que de las iluminaciones. La impregnación, la conjugación, la genminaridad sorı formas de creación más sutiles que los desarrollos causales ${ }^{12}$.

Una vez más, Lezama le resta importancia a la causalidad y le otorga la primacía a la chispa creadora y a los procesos que fomentan su aparición: la impregnación, la conjugación y la "genminaridad". Estos tres procesos forman parte de las actividades poéticas fundamentales que él llama "asimilación creadora" e "imaginación retrospectiva".

Como lector, escritor y ensayista, Lezama se vale de la misma técnica: Por medio de la yuxtaposición de elementos inesperados, espera provocar la chispa de la revelación. Estos agrupamientos, que a primera vista pueden antojárseles al lector como caprichosos, frecuentemente rinden fruto en sus manos. Anticipando la resistencia a estas ideas suyas, Lezama defiende su método en "A partir de la poesía":

Fulgurantes agrupamientos, que en un instante o en cualquier unidad de tiempo, establecen como una clave, una familia, una semejanza en lo errante o inadvertido. Claves que no existen en una demorada casa temporal, sino impuestas por u na circunstancia, un agru pamiento aparentemente caprichoso o fatal, pero que establece una division por gestos o actitudes, por acudimientos o inhibiciones ... Nada más lejos de poder contentarnos con la creencia de que son agrupamientos banales o dictados por el capricho $(2,827)$.

11 The Anxiety of In/luence, 30.

${ }^{12}$ Interrogando a Lezama Lima 53. 
Estos fulgurantes agrupamientos, según Lezama, ofrecen una clave en virtud de las homologias que resaltan de la circunstancia impuesta (el agrupamiento que hace el poeta). En definitiva, la defensa de su método se halla en su misma práctica y en sus resultados.

Más allá de su función estrictamente creadora, Lezama le confiere una đimensión étnica a la "asimilación creadora", ya que representa el rasgo cultural que define lo americano. Lezama mantiene que la asimilación creadora es una característica peculiar del escritor americano, consecuencia de la experiencia histórica del colonialismo. Comó participantes de la cultura europea solamente por medio de la herencia ilegítima de la colonia, el escritor americano puede compartir cualquier tradición cultural que le atraiga, sin compromiso alguno. En este aspecto, Lezama sigue el ejemplo del propio Martí, cuyo estilo y repertorio cultural no aceptaban límites, ni cronológicos ni geográficos. Para recalcar esta prerrogativa americana, Lezama contrasta las actitudes de dos escritores europeos hacia Goethe con su propia postura:

En nuestra época, por ejemplo, Gide lo ama, Claudel lo detesta. Pero yo como americano, puedo permitirme otra voluptuosidad inteligente, admirar a Claudel, y amar a Goethe .... Martf como americano, podía permitirse ese esplendor de la asimilación creadora ${ }^{13}$.

Como vimos antes, el paradigma de Martí como quintaesencia del escritor cubano y americano, recurre en la obra de Lezama, pero no sólo a fuero de su ideología, sino también porque Lezama lo considera un maestro de la asimilación creadora. Es evidente que a Lezama le atraen ciertos rasgos de la prosa de Marti, y sobre todo un empleo figurativo de la historia y de la cultura muy afín al suyo.

"Influencias en busca de Martí" ofrece un excelente modelo de asimilación creadora. En él, Lezama busca resonancias de la prosa de Martí en las cartas de Antonio Pérez, el poderoso secretario de Felipe II. Anticipándose por 18 años al concepto del apophrades (es decir, que los grandes poetas a veces logran dejarnos con la impresión de que sus precursores los imitan a ellos) articulado por Bloom, Lezama siente la marca de Martí en la escritura de Antonio Pérez.

Un examen detenido del ensayo revela la compleja operación de la "imaginación retrospectiva" en Lezama. Aunque la comparación entre Martí y Antonio Pérez en realidad depende de una cuestión de influencia, o, al menos, la suposición de que el poeta cubano debió leer a Pérez durante su estancia en Zaragoza, Lezama atenúa ese aspecto a favor de la "genminaridad". La lectura de Pérez que hace Martí no se ve como el primer paso en un proceso de imitación, sino como un momento de revelación. Al leer al cortesano, el poeta cubano no

${ }^{13}$ Interrogando a Lezama Lima, 73. 
lo escoge como modelo, sino que reconoce o "recuerda" su propio estilo en la prosa del precursor. No es difícil percibir la relación estrecha que existe entre el concepto de "asimilación creadora" que hemos estado discutiendo y el de "reminiscencia reconstructiva", el papel de la memoria en ese proceso de asimilación. El proceso de reminiscencia reconstructiva ha de comprenderse en lérminos de la tradición cristiana de interpretación figurativa explicada por Erich Auerbach ${ }^{14}$ :

Figural interpretation establishes a connection between two events or persons, the first of which signifies not only itself but also the second, while the second encompasses or fulfills the first. The two poles of the figure are separate in time, but both, being real events or figures, are within time, within the stream of historical life (p. 53).

De acuerdo con la estructura de la interpretación figurativa, la perspectiva que tiene Lezama de Pérez y de Martí es, a la vez, histórica y alegórica:

Since in figural interpretation one thing stands for another, since one thing represents and signifies the other, figural interpretation is "allegorical" in the widest sense. But it differs from most of the allegorical forms known to us by the historicity both of the sign and what it signifies (p. 54).

Lo que parece ser la caprichosa yuxtaposición de los estilos literarios de dos hombres separados por tres siglos es, en realidad, una compleja y rica maniobra poética mediante la cual Lezama "conjuga", no sólo los estilos de José Martí y de Antonio Pérez, sino también el valor histórico y figurativo de ambos hombres. Durante su primer exilio en España, Martí vivió en Zaragoza y presenció su gallarda e inútil defensa de la República en 1874. Este hecho biográfico le recuerda a Lezama los motines en defensa de los Fueros de Aragón, motivados por la fuga de Pérez de su prisión en Madrid, y su búsqueda de asilo en Zaragoza ${ }^{15}$. Lezama explota esta concurrencia histórica y geográfica:

Entonces llegó a lo que Antonio Pérez había dejado con caballos voladores y el peso de sus secretos, para apoderarse de la herencia del motín popular, José Martí. No recoge la lengua escrita de Baltasar Gracián, sino las ordenes y avisos que Antonio Pérez transparentaba a través de los tabiques carcelarios para avivar la espera de los amotinados de afuera. La lengua de Antonio Pérez

\footnotetext{
${ }^{14}$ Erich Aucrbach, "Figura", Scenes from the Drama of European Literaiure. Six Essays (Gloucester, Massachusetts: Peter Smith, 1973) 11-71.

${ }_{26}$ Véase Jorge Mañach, Marti el apóstol (La Habana: Editora Popular) 60-62. Para Antonio Pérez la mejor fuente es Gregorio Marañón, Antonio Pérez (El hombre, el drama, la época) 6th ed., 2 vols. (Madrid: Espasa-Calpe, 1958). Ver también John Lynch, Spain under the Habsburgs 2 tomos (Oxford: Basil Blackwell, 1965) 337-345.
} 
es la de las cartas y la de los consejos que da a reyes y a principales. El idioma conversa, con las interrupciones que le suelian los escuchas en personas o en sombra, traza nudillos por el aliento varonil y sentencias extraídas con la yesca de la averiguación inmediata y presente.

En Zaragoza, Martí siente las vivencias del destierro de Antonio Pérez. La obsequiosidad principal y la tierna despedida en las cartas del secretario, deben haber sido leídas por Marti, avivadas la junturas de ambos destierros. "Señora, si hubiese por allá unas manos - dice a la hermana del Bearnés, que es de quien más se fía-guárdemelas V.A.; que las he menester más que un manco". Cómo Martí sentiría esos bandazos suaves, esos toques resbalantes y cariciosos, donde su ternura parece adquirir la textura de una piel clásica y de buena compañía. En otra carta enviada a Enrique IV, rompe su escritura con esos creados halagos cariñosos, lan del gusto de Martí: "Envío a V.M. el agua de los ojos del alma, Señor, y de las entrañas más la destilaria yo muy alegre para vuestra salud y vida sino que estoy ya todo seco, y aun para una destilación, inútil ya. De donde me vengo a aborrecer yo mismo, porque cuando no soy de provecho para quien amo, no me querría ver" $(2,504-505)$.

La asociación de Martí y Pérez en términos politicos, impensable desde el punto de vista de nuestros historiadores contemporáneos, se explica perfectamente dada la interpretación que los historiadores románticos le dieron a los hechos de 1591. Gregorio Marañón ha comentado la deformación romántica de el significado verdadero de los fueros ${ }^{16}$. Los historiadores liberales, a quienes Marañón corrige, son, por supuesto, los historiadores que formaron el concepto que tenía Martí de la historia española. Ellos, como Martí, proyectaron su antimonarquismo y su lucha por una república (en España y Cuba respectivamente) sobre lo que, esencialmente, habia sido una pugna entre señores feudales y un monarca que buscaba la solidificación de una nación emergente. Para Martí y los historiadores liberales, sin embargo, no cabía duda alguna: los aragoneses, y en particular los zaragozanos, eran protorepublicanos que se opusieron a la tiranía de Felipe II, y el papel de Antonio Pérez, como instigador del breve y malhadado motín, era visto como un acto valiente de patriotismo, en vez de la intentona traicionera de un cortesano caido en desgracia.

\section{MARTI Y EL USO FIGURATIVO DE LA HISTORIA}

Para Martí, Felipe II, más que un personaje de la historia, era un emblema cultural que personificaba todo lo malo de España, no sólo en el siglo XVI, sino hasta sus días. Un artículo publicado por La Opinión Nacional de Caracas en diciembre 28, 1881, en el cual Marti reporta las actualidades de España, ofrece un ejemplo excelente de su aplicación de emblemas tomados de la España de los Habsburgos a la situación contemporánea. El artículo, que en varios rasgos

16 Marañon, $483-484$. 
recuerda los ensayos de Lezama, demuestra que Martí era un maestro de la asimilación creadora.

La revolución, que ha tomado del brazo al Monarca, procura arrebatarlo a su s huestes naturales y apartarlo de su vieja silla de oro, y la Iglesia, madre de la Monarquía, fulmina sus anatemas contra la revolución. Los nobles andan divididos y se amparan los unos de Ia Iglesia y los otros movidos de aquel espíritu que animó a Juan de Lanuza y halló feliz forma poética en García del Castañar, combaten en el campo nuevo .... Las instituciones vicjas ... Intentan sofocar la voz de la naturaleza humana. Blanden aún el estandarte verde de los autos de fe. Besarian aún, con labios amantes la mano huesosa y fría de aquel monarca tenebroso y lívido .... Las instituciones vicjas acaparan las armaduras oxidadas de los Muscos Reales, las carrozas carcomidas de Juana la Loca y Carlos II, las estatuas de piedra de los monarcas góticos, los atriles gigantescos que sustentan en bordado espaldar de bronce, misales corpulentos, en cuyas páginas de rugoso pergamino dibujaron letras negras y rojas los monjes demacrados y sombríos de Zurbarán y Ribera; y con todas esas históricas riquezas alzan barricada a la cohorte batalladora de la época, que viene calle arriba, en gran tren de vapor, cargada de piquetes, de arados, de libros, de buques, de dragas, de limas que rebajan montes, de botones eléctricos que hacen volar islas, de cuchillas que sajan las cordilleras y echan a hervir juntos en la colosal herida los apartados y rugientes mares! ${ }^{17}$ ?

Arguyendo la inevitable evolución hacia una monarquía constitucional, Martí pinta la contienda por medio de dos grupos de imágenes: a la España conservadora la representan Felipe II, la Inquisición, y la Iglesia, tétricamente evocada por la imagen compuesta de los monjes de Zurbarán y de Ribera, y los bellos pero apabullantes atriles. A la España conservadora se le opone la avalancha del mundo moderno, popular, y tecnológico. Los atriles son enfrentados por libros modernos, y las carrozas carcomidas por imágenes futuristas de trenes, vapores, palas mecánicas que abren canales, iy botones eléctricos que destruyen islas enteras! Aquí el entusiasmo tecnológico de Martí recuerda a Jules Verne, quien, como Cortázar ha demostrado, era autor favorito de Lezama ${ }^{18}$.

\section{EL IDIOMA CONVERSA.}

Aunque nunca se le menciona en "Influencias en busca de Marti", è poema, "Para Aragón en España", es, sin duda, el texto que motiva el nexo entre Antonio Pérez y José Martí. Es la matriz sobre la cual Lezama elabora su fulgurante agrupamien to. En el concepto poético e ideológico de la historia que tiene Martí,

\footnotetext{
${ }^{17}$ José Mart, Obras completas, 26 vols. (La Habana: Editorial Nacional de Cuba, 1963. 1966) 14, 263-264.

18 Julio Cortázar, "Para llegar a Lezama Lima", La vuelta al día en ochenla mundos (Madrid: Siglo 21, 1974) 42-43.
} 
hay dos Españas en pugna constante desde el siglo XVI: la España obscurantista y tiránica de Felipe II, y la España amante de la libertad que él ve encarnada, en especial, por la historia rebelde de Zaragoza y el carácter independiente de los aragoneses. Aunque este doble concepto de España siempre está presente en su obra, su defensa de la España libre nunca es tan elocuente ni sentida como en el conocido Verso Sencillo VII. El poema contiene la adhesión ideológica de Martí a las tradiciones históricas de Aragón (“Allá, en la vega florida,/La de la heroica defensa,/Por mantener lo que piensa/Juega la gente la vida"), y sus vinculos emotivos con una ciudad donde fue feliz. También alude a los hechos de 1591, como en el artículo de La Opinión Nacional, por medio de Juan de Lanuza ("Quiero el Pilar azuloso/De Lanuza y de Padilla"), el joven Justicia de Aragón ejecutado por Felipe II en la sangrienta represión de la revuelta.

El poema, sin embargo, of rece otro ejemplo de genminaridad entre Martiy Lezama. Ningún comentador de Martí ha podido asociar al Padilla mencionado en el poema con Aragón. El único personaje histórico apropiado sería Juan de Padilla, uno de los cabecillas de la revuelta de los Comuneros, pero ese Padilla. era toledano y fue ejecutado por Carlos V en $1521^{19}$. Si, como parece, Martí cometió un error, es un error muy interesante ya que se equivoca desde el punto de vista histórico, pero tiene toda la razón desde el punto de vista figurativo. La revuelta de los Comuneros es análoga al motín sobre los Fueros en Áragón. Ambos Lanuza y Padilla son, por lo tanto, emblemas del desafio regional ante la corona, y víctimas de la autocracia. El error de Marti también tiene otro interés: es precisamente el tipo de error que Lezama suele cometer. Lezama suele errar con respecto a los hechos, pero casi nunca en la explotación simbólica de esos hechos.

Para concluir, en un modo que recuerda el fulgurante agrupamiento de Lezama, que sirve de resorte en "Influencias en busca de Marti" (Zaragoza, motín, exilio, lucha antimonarquista, cartas de exiliados), "Para Aragón en España" reúne todos los elementos necesarios para establecer la deseada equiparación ideológica entre aragoneses y cubanos: "Estimo a quien de un revés/Echa por tierra a un tirano:/Lo estimo, si es un cubano;/Lo estimo, si aragonés". El uso figurativo que hace Lezama de personajes históricos refleja la explotación emblemática de la historia que lleva a cabo Martí.

Investigando sobre Antonio Pérez, yo mismo experimenté un momento de escalofriante genminaridad; como el que Lezama habrá vivido al leer las cartas del Secretario y sentir la marca de Martí. En el libro de Marañón leí: "Conoció Pérez, dice el Conde de Luna, 'que pues habían llegado a darle tormento, era. descoronada la flor de su vida" $(1,471)$. Recordé que la metáfora que el Conde de Luna le presta a Pérez es también de Martí, la misma que emplea para

19 Lynch, 1, 40. 
caracterizar lo que en su caso fue una temporada feliz en Aragón: "Donde rompió su corolahla poca flor de mi vida". Me pareció oír una carcajada ahogada de Lezama y un resonante "El idioma conversa". 
